\title{
Whose wellbeing is it anyway?
}

\section{Sunny Dhillon}

Bishop Grosseteste University, UK

\section{Abstract}

In this opinion piece, I suggest the need for a critical examination of the 'wellbeing' agenda currently being developed throughout Higher Education (HE) in the UK. I suggest that problems arise when notions of 'wellbeing' are used without being sufficiently well-defined, and are then accepted as the barometer of student health. This approach will be elucidated by contextualising the situation students find themselves in contemporary neoliberal universities; situating the crucial intermediary role that learning developers and student support services fulfil between academics and students; and exploring different modes of engagement available to those in these roles. Drawing upon the critical pedagogy of Biesta (2013), I argue that the remit of cultivating critical thinking and independent study skills means that learning developers, through one-to-one meetings, may sometimes be as well-placed as those with specific wellbeing roles (such as counsellors or mental health workers) to acknowledge and explore students' personal and social anxieties and concerns with compassion. This approach may seem to be at odds with wellbeing rhetoric, which, I argue, can act to detract from critical engagement with the explicit challenges facing students in the contemporary socio-political milieu. My aim is therefore to reintroduce the notion of criticality within the discussions taking place among academics and professional support staff, which in turn may inform practice. Central to my aim in this is to raise broader questions around the primary role of academics and professionals in HE; for example, is it to train students to passively 'fit in' within society or to educate them in a manner such that they will act agentively in society?

Keywords: critical thinking; neoliberalism; pedagogy of discomfort; wellbeing. 


\section{Introduction}

I have been in the post of Learning Development Tutor at Bishop Grosseteste University (BGU), a small, Cathedrals Group university in Lincoln, since Autumn 2016. I also teach as Visiting Tutor on a final year, undergraduate module within the BA Theology, Ethics and Society course. The institution has approximately 3,000 students, $85 \%$ of whom are female and $60 \%$ of whom are enrolled on education related subjects (BA Education Studies, PGCE Primary and Secondary among others). The students with whom I work are actively exposed to critical pedagogies (such as Paolo Freire's Pedagogy of the Oppressed,1968, and Ivan Illich's Deschooling Society,1970, for example) and often struggle with negotiating such radical educational theories with the practices that they encounter on placements. These struggles often become apparent during one-to-one learning development appointments, in module workshops, as well as in writing, especially discourse analysis assignments. It is within this context that I have experienced the wellbeing agenda being rolled out across the nation, from top down (e.g. Department for Work and Pensions, 2013; NHS, 2016; Department of Health and Social Care, 2017), ostensibly to help HE providers better take care of their students. That said, the widespread, uncritical take up of the wellbeing agenda within HE has not simply been a response to the injunctions of government, nor the logic of neoliberal economic policies. Rather, concerns expressed over the declining mental health and wellbeing (where the two terms are often used synonymously within HE discourse) of young people, due to a presumed combination of academic, financial and social pressures (ONS, 2018), have led to the emergence of the 'therapeutic university' (Ecclestone and Hayes, 2009; Furedi, 2017). Unlike the Social and Emotional Learning (SEAL) programme (Hallam, 2009; Watson et al., 2012) which has been rolled out across primary and secondary education within the UK, no such universal provision has been implemented in HE. Rather, each institution has been responding to the question of student wellbeing in an ad-hoc fashion.

At BGU's annual Learning and Teaching conference in June 2017, Pauline Hanesworth (HEA Academic Lead, Equality and Diversity) delivered a workshop to raise the awareness of academic and professional support staff on how to best ensure students' holistic wellbeing. Hanesworth grounded the need for this awareness through the research outlined in the graph below.

\section{Figure 1. The 2016 Student Academic Experience Survey.}


Student wellbeing: Neves, J. and Hillman N. (2016)

The 2016 Student Academic Experience Survey.

HEPI and HEA: p. 31

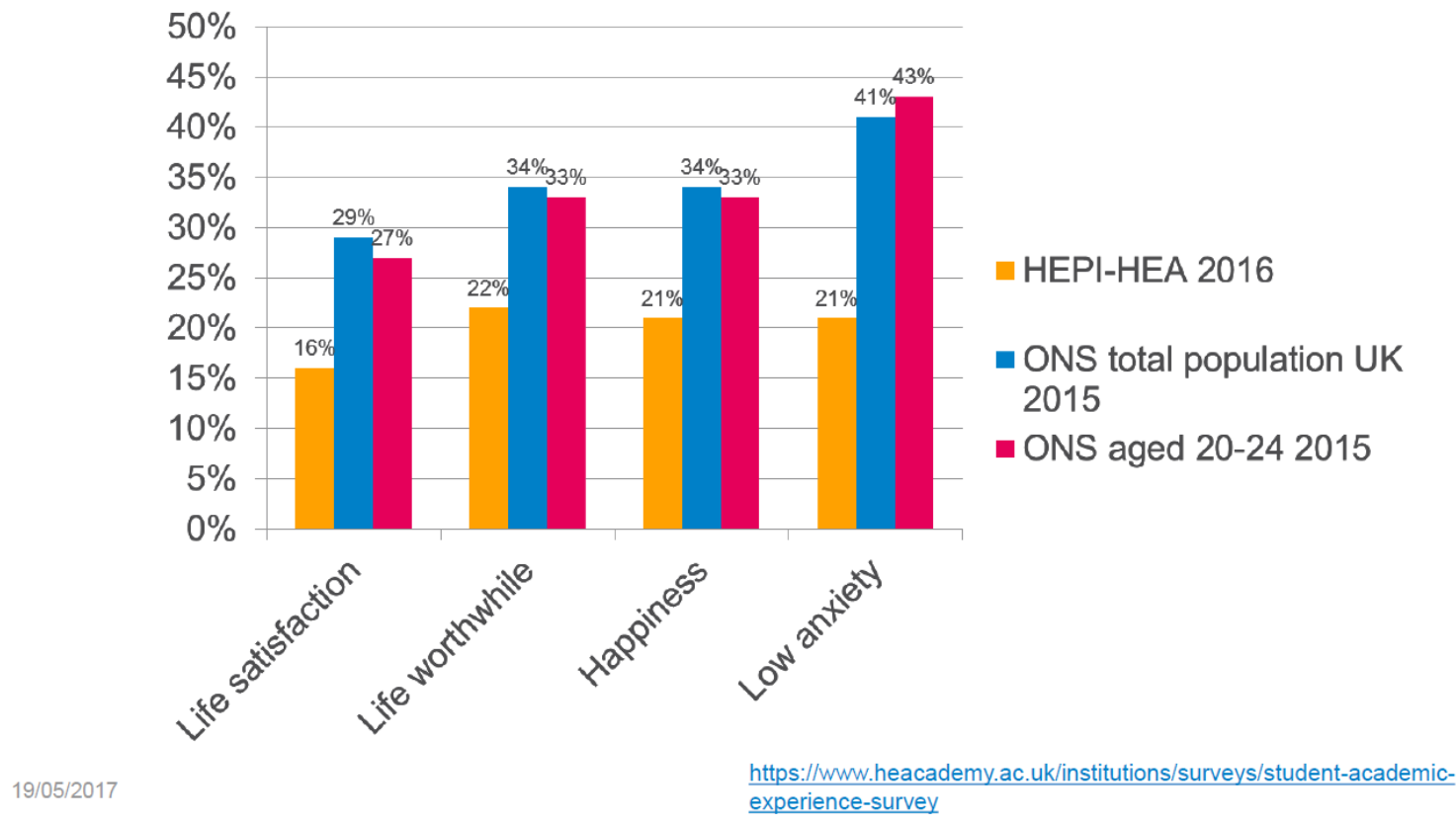

Hanesworth reported that this data demonstrated that the UK HE student population reported lower levels of life satisfaction, worthwhileness and happiness, as well as higher levels of anxiety, than either the general population at large, or the $20-24$ year old demographic not within HE. This research on behalf of the Higher Education Policy Institute (HEPI) and Higher Education Academy (HEA, now Advance HE) by Neves and Hillman (2016) informed subsequent work by Houghton and Anderson (2017), which aimed to embed student mental wellbeing across HE curricula, suggesting that both academic and support staff become 'agents of wellbeing'.

An obvious problem with expecting all academics and support staff to become agents of wellbeing is that, up to now, few have received training in counselling skills or mental health awareness. In addition, in my experience, many such staff would not see such a role as their responsibility. However, as evidenced in reports such as that of Hanesworth (2017), Broglia et al (2017) and Thornley (2017), the culture of HE appears to be changing. These documents describe attempts to analyse the problems students face and institutional responses in terms of resource allocation policy making. They also report the increase in uptake of training from organisations such as Mind and Rethink Mental IIIness, as well as the growth of services such as the online peer-support group Big White Wall (2018). 
Biesta (2013, p.67) argues that such an approach of training staff to offer counselling to students turns problems arising from the broad socio-economic context and issues surrounding political governance into the responsibility of individual teachers and learners. The current socio-economic policy climate is that of neoliberalism (Ball, 1997; Bourdieu, 1998; Giroux, 2002 and 2014; Ward, 2012; Radice, 2013). In this culture, organisations from cancer charities to HE providers are subject to the same logic of privatisation and competition. This results in a situation whereby individuals are encouraged to shape and sell themselves as marketable commodities to attract viable bidders, be they employers, educational providers, or even voluntary organisations. The neoliberal economic and political climate can be seen to render academics and HE support staff as agents of wellbeing as part of a process Foucault refers to as 'governmentality' (1991). In this case attention is deflected from the social and economic policies (e.g. the introduction of fees and creation of student indebtedness), which have contributed to the wellbeing crises by redefining the 'problems' (e.g. resilience, employability) as mainly the responsibility of individuals rather than society. Biesta (2013) also discusses the insidiousness of rampant neoliberal competition and the ill effects of it upon students' wellbeing, arguing that 'the fact that individuals are made responsible for keeping up their employability in rapidly changing global markets' obfuscates the critical question as to 'why such markets should rule over the economy and over social and political life more generally in the first place' (p.67). A key element in my argument is therefore that it is unsurprising that students are struggling with their overall wellbeing in an age of rising student debt, zero-hour contracts, rising wealth inequalities, and what Guy Standing (an advocate of a basic income for all) dubs the era of the 'precariat' (2016).

\section{'It is no measure of health to be well adjusted to a profoundly sick society'}

The observation above by Jiddu Krishnamurti (n.d) is the fundamental basis of this paper. It is clear that students in the contemporary neoliberal HE apparatus are subject to economic challenges and fierce competition for employment on a global scale at levels not witnessed since the aftermath of the Second World War (Dorling, 2015a; Lansley and Mack, 2015; Standing, 2016; Wilkinson and Pickett, 2010 and 2018). It is not within the scope of this opinion piece to give a full and detailed account of the challenges students face (see Dorling 2015a and 2015b in particular). Taking as a given that the socio- 
economic reality is tough for all but a small minority of economically privileged students, I suggest working from the - albeit exaggerated - Adornian premise that 'where everything is bad it must be good to know the worst' (2005, p.83). In accepting that students face tangible and harsh challenges, as a deliberately provocative thought experiment, I propose three responses:

1. Medication with a Huxley-esque soma.

2. Learning Development Gyms.

3. 'Pull up your bootstraps' training.

Route one is inspired by Aldous Huxley's 1932 dystopian/utopian novel Brave New World, whereby a pill named soma is administered to the populace free of charge by the governing powers-that-be in order to induce a sense of contentment with the socio-political reality in which citizens reside. Doing so, the powers-that-be nullify any critical engagement with material conditions, and in so doing, any potential revolt.

Route two draws upon the notion that whilst paying for a gym membership does not make one fit, working alongside a qualified trainer to achieve goals through diligence and a great deal of effort and commitment can, and usually does. In this way, in the role of an academic and/or professional support staff in learning development, for example, one is akin to a gym trainer, and can therefore enable students to develop their critical thinking skills and independence of thought. Through embedded workshops and one-to-one sessions, learning developers could help students to develop their academic strength, flexibility and skills. Like all effective trainers, learning developers can push, challenge and encourage students to channel their energies, and - often-legitimate - anger and frustrations, in a constructive manner; in effect, to confront and reshape the socio-political conditions in which they reside (Peelo, 1994; Wisker et al., 2008; Hartley et al., 2010; Brookfield, 2017; Ashton and Stone, 2018).

Route three assumes that students in today's HE have never had it so good in terms of technological advances, opportunities and infrastructure, and that they ought not to expend time and energy complaining about, or criticising, the status quo but, rather, that they ought to be positive, count their blessings and, in effect, get with the programme of neoliberal competition. This route puts the onus squarely upon the students' shoulders and 
argues that they are wholly responsible for what happens to them in terms of learning and employment goals.

It is clear that route three is rather crude, and fails to address the wider socio-economic and political challenges that students face. What is not so clear to me is how route one differs in its aims to the wellbeing agenda currently in vogue within HE in the UK. Policies which encourage academics and support staff to respond to students' difficulties, frustrations, anger and criticisms of their HE experiences by referring them for wellbeing support, produce collusion with the neoliberal agenda and serve to stifle or deflect opposition to the status quo. In my mind, this raises a central philosophical and pedagogical question about what the underlying principle of the contemporary university is. If it is to create compliant employees, who will follow orders uncritically, then perhaps route one is apt. If it is to create critical, independent thinkers, then routes one and three clearly fall short, but route two might be productive.

\section{Wellbeing Symptoms}

The rationale of the wellbeing agenda within the contemporary, neoliberal HE arena is that it will result in students exhibiting a higher rate of happiness, life satisfaction, feelings of worthwhileness, as well as lower anxiety, and that educational providers have an obligation to provide embedded services within curricula to deliver this. Facing acute challenges such as the cost of education, housing, existing plutocracies and social injustice, it is no leap to assert that the four symptoms outlined above are inextricably linked to the socio-economic and political milieu in which students (and staff alike) find themselves. However, this acknowledgement is conspicuous by its absence in the HEA reports (Hanesworth 2016 and 2017; Houghton and Anderson, 2017). Again, following my provocative line of thought, as agents of wellbeing, HE providers might be seen as delivering Huxley-esque soma whereby petting animals, undertaking mindfulness meditation and aligning one's chakras through dance (all of which actually form part of BGU's wellbeing roster of activities) promise to produce feelings of life satisfaction, happiness, worthwhileness and to reduce anxiety - and that this is preferable to challenging students to analyse their socio-political conditions and provoke critical discourse. Such wellbeing interventions may well be effective, but, in my view, they would need to work alongside the development of critical discourse. I would expect higher 
education to be channelling students' righteous sense of indignation with existing sociomaterial conditions, together with developing creative proposals for reform and change.

Where I find the wellbeing agenda to be at its most unnerving is where it purports to put students' wellbeing at front and centre (Seldon and Martin, 2017) but, in my view, exacerbates existing social problems by individualising them. The underlying mantra appears to be 'things may be tough but don't worry, we're here to help you feel better'. I am not calling for route three and a stoic attitude which some might think almost revels in student discomfort, but, rather, route two, which should encourage a challenging engagement with the roots of existing injustice and inequality. Merely enacting a route one approach through short-term wellbeing activities such as mindfulness workshops will only serve to leave existing social injustices unexamined in the longer-term.

\section{Individualisation of Social Problems}

As Allen and Bull (2017) argue in their WONKHE blog post: 'the focus upon individual responsibility is both telling and deeply worrying that there is no mention of wider conditions affecting young people's mental health such as mounting debt; a housing crisis; and an uncertain graduate labour market'. Moreover, as Kristiina Brunila (2013) asserts, depoliticising students' wellbeing leads to individualisation of the problems that they face and creates a culture whereby mindset alone is seen as key to growth and attainment, rather than wider material and social conditions. Brunila continues by arguing that in a neoliberal culture, where individuals themselves are rendered commodities, and are required to make themselves fit for service and exchange, without critiquing the necessity to do so, or, at the very least, making such critique marketable, 'one learns to find mistakes in oneself and then hold oneself to blame. This is one way to keep individuals busy by focusing on themselves and making their whole lives available for the interests of the market and the state' (p.226). Route one is wholly complicit with this depoliticised approach, and nullifies critical social engagement in the interest of maintaining the status quo by ensuring that individuals 'get with the programme'.

Therefore, in promoting the proliferation of soma-esque coping and/or avoidance techniques to ensure that students get with the programme and do not suffer any crises of conscience or angst in the face of alterable material conditions, I argue that the wellbeing agenda as route one not only distracts from critical social engagement, but is also 
problematic insofar as it is opaque to a 'wider social, political and intellectual framing. When viewed in this light, embracing positive psychology - for example - in UK universities is a dangerous route to travel' (Allen and Bull, 2017).

\section{BGU Learning Outcomes}

BGU's Learning Outcomes 2017/18 state within the first four aims that students who graduate from the university will be able to:

- Think and challenge independently, critically and imaginatively.

- Be intellectually curious and accept ambiguity.

I argue that it is not possible to undertake these processes if one is feeling completely 'well' about the situation in which they find themselves. To challenge and accept ambiguity necessarily involves going against the status quo and risking marginalisation. Students who are successfully able to enact these learning outcomes will arguably experience illeffects to their wellbeing, as per the definition of the latter by the criteria provided in figure 1 above by Advance HE. In effect, their level of happiness will likely fall, and their anxiety levels are likely to rise. For example, to critically engage with Illich or Freire will most likely lead to what Ronald Barnett (2011) refers to as epistemological uncertainty (p.121).

Whilst it is apparent that route three is a crude approach that actively disregards the possible legitimacy of a sense of injustice with existing socio-material conditions, route one is clearly not an appropriate manner of cultivating the BGU Learning Outcomes either. Therefore, route two of the gym-esque trainer is the most appropriate course of action to meet these criteria. This manner of student engagement provides an underlying pedagogical rationale that allows academic and support staff to encourage students to criticality engage with normative discourse. Moreover, it permits staff and students alike to build the confidence to ask awkward 'why' questions and to then foster an environment in which to explore the consequences of entering into the proverbial rabbit hole. Maxine Greene is an insightful voice in this regard. She argues that learning depends upon 'breaking free, a leap, and then a question, and that the educative task is to create situations in which students are moved to begin to ask, in all the tones of voice that there are, "why?"' (Greene, 2000, p.6). Encouraging students to enter the rabbit hole and 
critically explore the situations in which they find themselves is something that those working within $\mathrm{HE}$, even under contemporary neoliberal governance, are in a crucial position to enact.

\section{Pedagogy of Discomfort}

Having established route two as the most appropriate course of action, I would like to expound upon the benefits of this pedagogy of discomfort before concluding the paper. Encouraging students to ask awkward 'why' questions fosters critical thinking. In so doing, students will be better equipped to challenge inequality and injustice in its myriad of forms. This process is inextricably an uncomfortable one. As a critic of what he deems the 'Happiness Industry', Will Davies (2015) claims that 'once people are critical or angry, they can also be critical or angry about something which is external to themselves' (p.199). Davies continues by arguing that de-individualising social concerns and engaging in critical discourse results in a less lonely, less depressive, less narcissistic state of affairs than one in which people wonder how their minds or brains are behaving, and what they should do to improve them' (p.200) under a logic of rampant neoliberal individual commodification. It could be argued that wellbeing activities that result in an increase in self-esteem, for example, address the ontological uncertainty (Barnett, 2011, p.121) students face and provide a more secure foundation from which to tackle the epistemological uncertainty faced through critical engagement with learning content. That said, a key problem of the wellbeing agenda amidst contemporary neoliberal governance is that it results, as outlined above, in the individualisation of responsibility in the face of wider socio-political issues. To reduce wellbeing to individual engagement with strategies and practices offered by $\mathrm{HE}$ providers is to distract attention from critical engagement with the conditions that have resulted in the need for a greater proliferation of wellbeing initiatives in the first instance.

In terms of practice as academics and learning developers, whilst we in these roles may not all be trained counsellors, to ignore, or seek to nullify, the affective quality of HE would be to do a disservice to the transformative power of pedagogy. We are not agents of wellbeing but, rather, professionals that can encourage independent, critical thinking. Henry Giroux is particularly instructive here. He argues that in our roles we have the capacity to allow students to be critical agents, to learn how to take risks, engage in thoughtful dialogue and address what it means to be socially responsible. In an interview published in a blog by Dawes, Giroux declares that: 
Pedagogy is not about training; it is about educating people to be self-reflective, critical and self-conscious about their relationship with others and to know something about their relationship with the larger world. Pedagogy in this sense not only provides important thoughtful and intellectual competencies; it also enables people to act effectively upon the societies in which they live.

Dawes, 2014

Acting effectively within the society in which students reside cannot take place if they do not critically engage with the status quo. If they reside and study in a state of fear and desire to integrate with the existing programme, then they cannot act upon societal conditions but, instead, merely survive within them. If pedagogy in $\mathrm{HE}$ is not about training students to be functionaries but to be self-reflective, critical and self-conscious about how they are situated within society, then in our professional roles we can be agents of criticality. Delivering one-to-ones in the role of a learning developer is a particularly ripe arena to encourage critical thinking in a 'safe' environment - that is, where ideas and concepts can be probed in a playful manner, even - with compassion. Megan Boler and Michalinos Zembylas (2003) observe that doing so 'nurtures emotions of anger or guilt but challenges them with compassion and courage - there will be possibilities for mutual exploration that also nurture hope and a sense of community for initiating change' (p.130). Boler and Zembylas continue by arguing that encouraging this pedagogy of discomfort 'invites critical inquiry regarding cherished beliefs and assumptions, and also calls for students and educators to take responsibility and even action in the collective struggle for social justice' (p.126). It is apparent that route two is best equipped to encourage a pedagogy of discomfort. A central issue is then, what professionals in HE deem their role to primarily entail: train students to fit within society or to educate in a manner such that students may act upon their socio-cultural milieu.

\section{Conclusion}

To summarise my view, the current wellbeing agenda being rolled out through $\mathrm{HE}$ in the UK is a dangerous path to travel. In effect, it enacts a logic of soma, whereby students are encouraged to become well-adjusted to the status quo. HE professionals are being encouraged by research conducted on behalf of HEPI (2016) and the HEA (2017) to become agents of wellbeing, in effect, to be complicit with route one. This agenda appears 
to have been taken on rather uncritically by some HE professionals. This paper does not argue for a route three logic and disavow HE professionals of any consideration of students' wellbeing but, rather, deems route two, a pedagogy of discomfort, the most appropriate course of option. This route can entail healthy practices such as meditation, yoga and appropriate diets, but, crucially, acknowledges that these practices are themselves inextricably enmeshed within a particular socio-economic and political discourse that constantly requires critical interrogation. In the late Howard Zinn's (2002) terms, it is impossible to remain neutral on a moving train. So, under a logic of neoliberalism, immanent responses to improve the wellbeing of subjects living under its dictates, be it through Cognitive Behavioural Therapy (CBT), Neuro Linguistic Programming (NLP) or, indeed, Mindfulness practices, for example, are therapeutic interventions which individualise social concerns, and thus unwittingly serve to maintain the status quo. As a result, these courses of action perpetuate a cycle of route one, shortterm agendas, to distract from the more central issue of wider socio-political governance. Doing yoga and the like in and of itself is, of course, not a political problem. The issue is whether doing so is to be undertaken to tolerate and survive amidst harsh socio-economic and political conditions or, preferably, to develop an inner resolve to critically engage with and challenge the presuppositions that scaffold the status quo. So, whilst wellbeing activities such as those outlined above can indeed tackle ontological uncertainty, and perhaps enable students to deal with epistemological uncertainty in a healthier manner, the fact that CBT and NLP, for example, are forms of therapy that, by virtue of the definition of 'therapy', seek to cure or remedy the individual such that they be fit for societal purpose, what results is an uncritical acceptance that social norms are, in fact, worthy of adapting oneself to. Hence, the status quo remains the barometer of health and wellbeing. As the late Mark Fisher (2012) observed: '[t]herapies such as cognitive behaviour therapy combine a focus on early life with the self-help doctrine that individuals can become masters of their own destiny'. In doing so, the individualisation of wellbeing is divorced from socio-political conditions and the individual becomes a commodity that must make her or himself fit and well for social function. This, at the very least, distracts from engaged socio-political critique and, at worst, is inimical to it, for it is based on the premise that 'all is well' but that the individual ought to adjust themselves to the status quo in order to be well.

HE academics and support staff do have opportunities to encourage students to critically explore the material conditions in which they reside. Moreover, they have the capacity to exercise compassion and support in terms of the very real challenges that students face. 
In my view, these activities are both at least as essential to HE as their other teaching and employability related goals. I would go so far as to argue, in the Socratic tradition, that contemporary students are in need of a little 'corruption' in the face of a one-sided neoliberal discourse. To conclude, through the words of Alain Badiou (2012) in the appropriately entitled Philosophy for Militants, 'to corrupt here means to teach the possibility of refusing all blind submission to established opinions. To corrupt means to give the youth certain means to change their opinion with regard to social norms, to substitute debate and rational critique over imitation and approval' (p.10).

\section{Author Details}

Sunny Dhillon has been a Learning Development Tutor at Bishop Grosseteste University, Lincoln, since 2016, and a PhD candidate within Cardiff University's Philosophy department for longer than he cares to remember (since 2011). 


\section{References}

Adorno, T. W. (2005) Minima Moralia: reflections from damaged life (Trans. E. F. N. Jephcott). London: Verso.

Allen, K. and Bull, A. (2017) 'Beware of the positive university', WONKHE, 2 October.Available at: http://wonkhe.com/blogs/beware-of-the-positive-university/ (Accessed: 3 October 2017).

Ashton, S. and Stone, R. (2018) An A-Z of creative teaching in higher education. Los Angeles: SAGE.

Badiou, A. (2012) Philosophy for militants (Trans. B. Bosteels). London: Verso.

Ball, S. J. (1997) 'Policy sociology and critical social research: a personal review of recent education policy and policy research', British Educational Research Journal 23(3), pp. 257-274.

Barnett, R. (2011) Being a University. London; New York: Routledge.

Biesta, G. J. J. (2013) The beautiful risk of education. Boulder, CO.: Paradigm.

Big White Wall (2018) Online mental health and wellbeing service, available at: https://www.bigwhitewall.com/v2/Home.aspx?ReturnUrl=\%2f (Accessed: date).

Boler, M. and Zembylas, M. (2003) 'Discomforting truths: the emotional terrain of understanding difference', pp. 110-136, in Trifonas, P., Giroux, H., and Pinar, W. (eds.) Pedagogies of difference: rethinking education for social change. New York: Routledge.

Bourdieu, P. (1998) 'The essence of neoliberalism' (Trans. J. J. Shapiro). Le Monde Diplomatique, 8 December. Available at: https://mondediplo.com/1998/12/08bourdieu\#tout-en-haut (Accessed: 30 May 2018).

Broglia, E., Millings, A. and Barkham, M. (2017) 'Challenges to addressing student mental health in embedded counselling services: a survey of UK higher and further education institutions', British Journal of Guidance \& Counselling, pp.1-15.

Brookfield, S. (2017) Becoming a critically reflective teacher, $2^{\text {nd }}$ edn. Somerset: John Wiley \& Sons.

Brunila, K. (2013) 'Hooked on a feeling: education, guidance and rehabilitation of youth at risk', Critical Studies in Education, 54(2), pp.215-228.

Davies, W. (2015) The Happiness Industry: how the government and big business sold us well-being. London: Verso.

Dawes, S. (2014) 'Interview with Henry A. Giroux: The Neoliberalisation of higher education'. Simon Dawes: Media Theory, History and Regulation, 26 June. Available at: https://smdawes.wordpress.com/2014/06/26/interview-with-henry-agiroux-the-neoliberalisation-of-higher-education/ (Accessed: 14 December 2017). 
Department of Health and Social Care (2017) Thousands of new roles to be created in mental health workforce plan, 31 July. Available at:

https://www.gov.uk/government/news/thousands-of-new-roles-to-be-created-inmental-health-workforce-plan (Accessed: 12 December 2017).

Department for Work and Pensions. (2013) Health, work and wellbeing - evidence and research. Available at: https://www.gov.uk/government/collections/health-work-andwellbeing-evidence-and-research (Accessed: 19 February 2018).

Dorling, D. (2015a) Inequality and the 1\%. London: Verso.

Dorling, D. (2015b) Injustice: why social inequality still persists. Bristol: Policy Press.

Ecclestone, K. and Hayes, D. (2009) The dangerous rise of therapeutic education. London: Routledge.

Fisher, M. (2012) 'Why mental health is a political issue', The Guardian, 16 July. Available at: https://www.theguardian.com/commentisfree/2012/jul/16/mental-health-politicalissue (Accessed: 12 December 2017).

Foucault, M. (1991) 'Governmentality' (Trans. R. Braidotti), pp. 87-104, in Burchell, G., Gordon, C. and Miller, P. (eds.) The Foucault Effect: Studies in Governmentality. Chicago, IL: University of Chicago Press.

Freire, P. (1968) Pedagogy of the oppressed. New York: Seabury Press.

Furedi, F. (2017) 'The Therapeutic University'. Frank Furedi: Sociologist, commentator and author. Available at: http://www.frankfuredi.com/site/article/898 (Accessed: 15 June 2018).

Giroux, H. (2002) 'Neoliberalism, corporate culture, and the promise of higher education: The university as a democratic public sphere'. Harvard Educational Review, 72(4), pp.425-464.

Giroux, H. (2014) Neoliberalism's war on higher education. Toronto: Haymarket Books.

Greene, M. (2000) Releasing the Imagination: essays on education, the arts and social change. San Francisco, CA.: Jossey-Bass.

Hallam, S. (2009) 'An evaluation of the Social and Emotional Aspects of Learning (SEAL) programme: promoting positive behaviours, effective learning and well-being in primary school children', Oxford Review of Education, 35(3), pp.313-330.

Hanesworth, P. (2016) Teach well: embedding mental wellbeing in the curriculum. York: Higher Education Academy.

Hanesworth, P. (2017) Promoting a holistic approach to student wellbeing: considering the curriculum (Higher Education Academy). Available at:

http://www.insidegovernment.co.uk/uploads/2017/05/paulinehanesworth.pdf (Accessed: 20 July 2017).

Hartley, P., Hilsdon, J., Keenan, C., Sinfield, S. and Verity, M. (2011) Learning development in higher education. Basingstoke, Hampshire; New York: Palgrave Macmillan. 
Houghton, A.M. and Anderson. J. (2017) Embedding mental wellbeing in the curriculum: maximising success in higher education. York: Higher Education Academy.

Huxley, A. (1977) Brave new world. London: Granada Publishing.

Illich, I. (1970) Deschooling society. New York: Harper and Row.

Lansley, A. and Mack, J. (2015) Breadline Britain: the rise of mass poverty. London: Oneworld.

Lawrence, J. L. (2017) Maximising success in higher education: embedding mental wellbeing in the curriculum toolkit. York: Higher Education Academy.

Neves, J. and Hillman, N. (2016) The 2016 Student Academic Experience Survey (Higher Education Policy Institute and Higher Education Academy). Available at: https://www.hepi.ac.uk/wp-content/uploads/2016/06/Student-Academic-ExperienceSurvey-2016.pdf (Accessed: 20 July 2017).

National Health Service (2016) Five steps to mental wellbeing, 6 January. Available at: https://www.nhs.uk/conditions/stress-anxiety-depression/improve-mental-wellbeing (Accessed: 21 September 2017).

Office for National Statistics (2018) Estimating suicide among higher education students, England and Wales: experimental statistics. Available at:

https://www.ons.gov.uk/peoplepopulationandcommunity/birthsdeathsandmarriages/ deaths/articles/estimatingsuicideamonghighereducationstudentsenglandandwalesex perimentalstatistics/2018-06-25 (Accessed: 2 July 2018).

Peelo, M. (1994) Helping students with study problems. Buckingham; Bristol, PA: Society for Research into Higher Education \& Open University Press.

Radice, H. (2013) 'How we got here: UK higher education under neoliberalism', ACME: An International E-Journal for Critical Geographies, 2013, 12(3), pp.407-418.

Seldon, A. and Martin, A. (2017) The positive and mindful university. Available at: https://www.hepi.ac.uk/wp-content/uploads/2017/09/Hepi-The-Positive-and-MindfulUniversity-Paper-18-Embargoed-until-21st-Sept-1.pdf (Accessed: 12 December 2017).

Standing, G. (2016) The corruption of capitalism: why rentiers thrive and work does not pay. London: Biteback.

Thornley, C. (2017) Not by degrees: Improving student mental health in the UK's Universities, IPPR. Available at http://www.ippr.org/research/publications/not-bydegrees (Accessed: 20 June 2018).

Ward, S. C. (2012) Neoliberalism and the global restructuring of knowledge and education. New York: Taylor \& Francis.

Wilkinson, R. and Pickett, K. (2010) The spirit level: why equality is better for everyone. London: Penguin. 
Wilkinson, R. and Pickett, K. (2018) The inner level: how more equal societies reduce stress, restore sanity and improve everyone's wellbeing. London: Penguin.

Watson, D., Emery, C., Bayliss, P., Boushel, M. and McInnes, K. (2012) Children's social and emotional well-being in schools: a critical perspective. Bristol: The Policy Press.

Wisker, G., Exley, K., Antoniou, M. and Ridley, P. (2008) Working one-to-one with students. New York: Routledge.

Zinn, H. (2002) You can't be neutral on a moving train: a personal history of our times. Boston: Beacon Press. 